\title{
Situações da Amazônia no Brasil e no continente
}

\author{
HERVÉ THÉRY
}

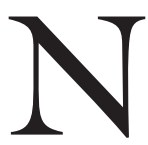
Ão SE FAla DA Amazônia como do Middle West dos Estados Unidos, das ilhas da Indonésia ou de outra região qualquer do mundo: em vez de observá-la objetivamente, de avaliar seus potenciais e suas limitações, de analisar as condições de vida dos seus habitantes, entra-se logo em considerações fortemente afetivas. Estas são inspiradas, ora por uma visão excessivamente pessimista, derivadas das lendas do "inferno verde", ora demasiadamente otimistas, vislumbrando nela imensas riquezas ainda ocultas, um "eldorado" ameaçado pela cobiça externa, seja ela estrangeira ou de outras partes do Brasil (geralmente o paulista no papel de vilão). É tempo de deixar de lado essas abordagens ultrapassadas, que enviesam tantos discursos sobre a Amazônia, e de tentar definir melhor a situação real da região no contexto nacional, em um momento onde as políticas para a região e a sua posição em relação ao resto do continente estão sendo reavaliadas.

Tratar-se-á, portanto, primeiro de analisar o peso real da Amazônia no Brasil, em termos econômicos e humanos. Em seguida, avaliar as ações públicas na Amazônia, cuja linha diretriz, apesar das mudanças políticas e de divergências internas, parece ser de mantê-la no papel de fronteira de expansão. Finalmente, em um momento onde os países da América do Sul se redescobrem, pois deixam de olhar separadamente para o Norte e começam a se aproximar de seus vizinhos, cabe repensar a situação da Amazônia, que passa subitamente de periferia do Brasil a centro do continente.

\section{O peso real da Amazônia no Brasil}

Uma maneira simples de abordar uma reavaliação da situação da Amazônia é começar por medir, por meio de vários indicadores territoriais e sociais, o que ela representa no conjunto nacional. Uma seleção de tais indicadores, de várias ordens (Figura 1), mostra a clara defasagem existente entre a superfície ocupada pela Amazônia - mais da metade do país - e o seu peso econômico e social, bem menor: se ela representa $60 \%$ da superfície do Brasil, seu PIB não passa de $5 \%$; ela reúne apenas $10 \%$ da população urbana, $12 \%$ da população total e um pouco mais - 14\% - dos migrantes recentes, das estradas, do número de municípios. O único indicador, pouco invejável, para o qual a Amazônia supera a sua cota de território, é o número de mortos em conflitos fundiários...

Em termos de população, a Amazônia legal continua sendo a parte menos povoada do país: mesmo tendo a região ganhado treze milhões de habitantes de 
1970 a 2000 (ou seja, aumentou 172\%, enquanto o país aumentava 82\%), ela continua representando apenas um pouco mais de $12 \%$ do total (contra $8 \% \mathrm{em}$ 1970) e as densidades continuam baixíssimas: a Amazônia legal só tem 4,2 habitantes por $\mathrm{km}^{2}$ (e o Estado de Amazonas apenas 1,8 ) enquanto a densidade nacional é de 20 habitantes por $\mathrm{km}^{2}$. Devido a essas baixas densidades, e a pressão pioneira vinda do Sul-Sudeste, a Amazônia continua sendo a grande reserva de espaço do país, a sua última fronteira de migração e de expansão.

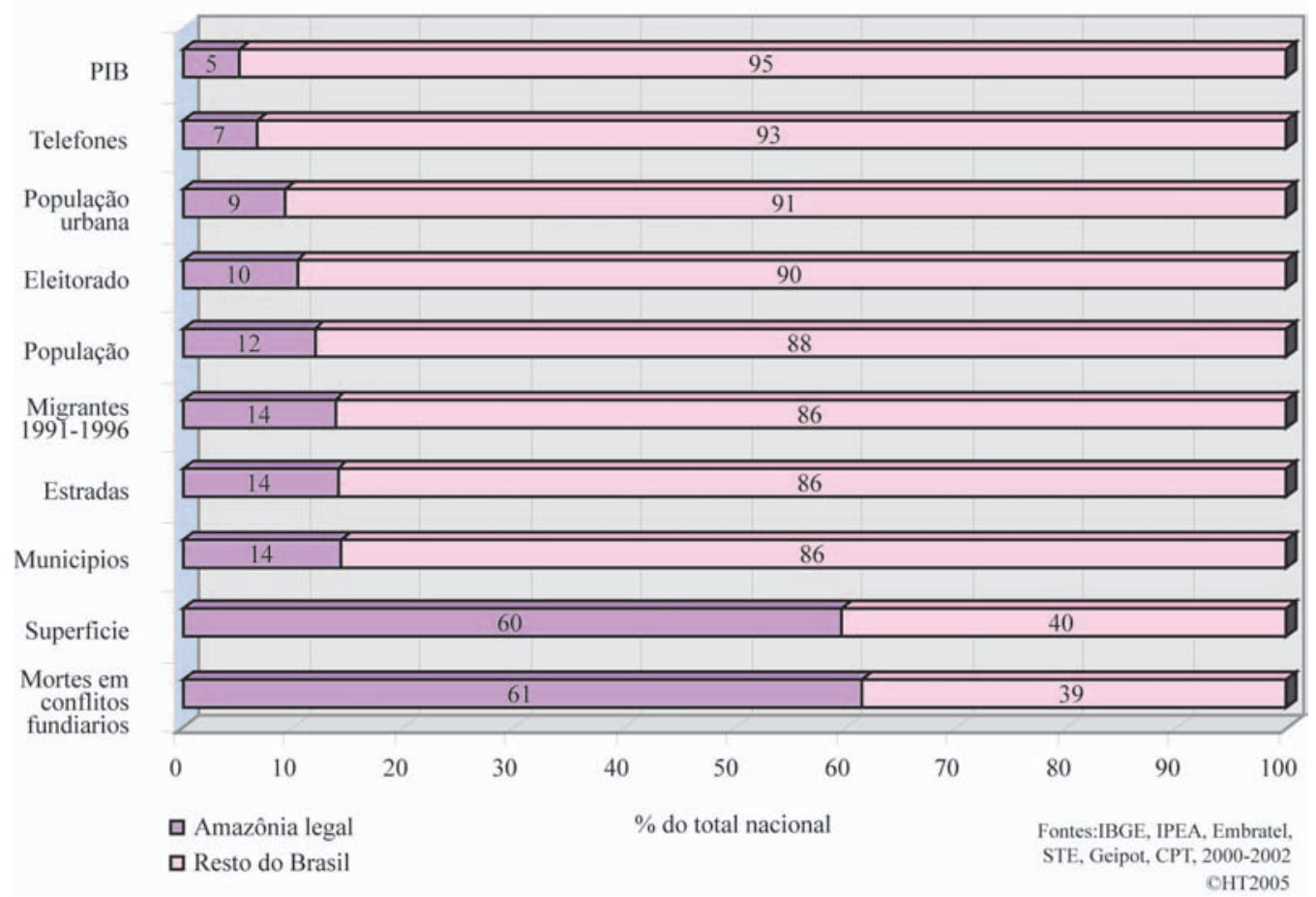

Figura l - Participação da Amazônia

Usando um critério mais qualitativo, o número de pesquisadores registrados no CNPq, a Amazônia também aparece numa situação difícil: com 3,8\% dos pesquisadores e $2,7 \%$ dos pesquisadores doutores (indicadores para os quais o estado de São Paulo representa respectivamente $29,7 \%$ e $34,7 \%$ do total nacional), ela é a última colocada entre as cinco regiões brasileiras, um fato que pesará sobre o seu futuro, já que a formação de elites científicas regionais é um requisito para um desenvolvimento sustentável.

Porém, a Amazônia está mudando, principalmente através dos impactos desencadeados pela abertura das rodovias que permitiram, a partir dos anos de 1960, a chegada de migrantes vindos de outras regiões e, com ela, vários tipos de efeitos, alguns claramente positivos, outros nem tanto. A construção dessas rodovias - mas, também, a melhoria das hidrovias e das redes de telecomunicações está mudando profundamente a situação da Amazônia, econômica e estrategicamente: apesar de todos os seus atrasos, ela pode achar nessa mudança novo ímpeto. 
A chegada das rodovias tem transformado profundamente a organização regional da região, até então definida em volta dos rios (Figura 2). Passou-se de um espaço reticular a outro, da Amazônia estruturada em função das vias navegáveis, drenando os fluxos para o Leste, a uma região dominada pelas estradas que levam ao Sul-Sudeste. E os "nós" dessas duas redes, as cidades que polarizam o espaço, não são os mesmos, o que levou à decadência de algumas e à ascensão de outras, uma redistribuição que alterou profundamente as hierarquias urbanas da região.

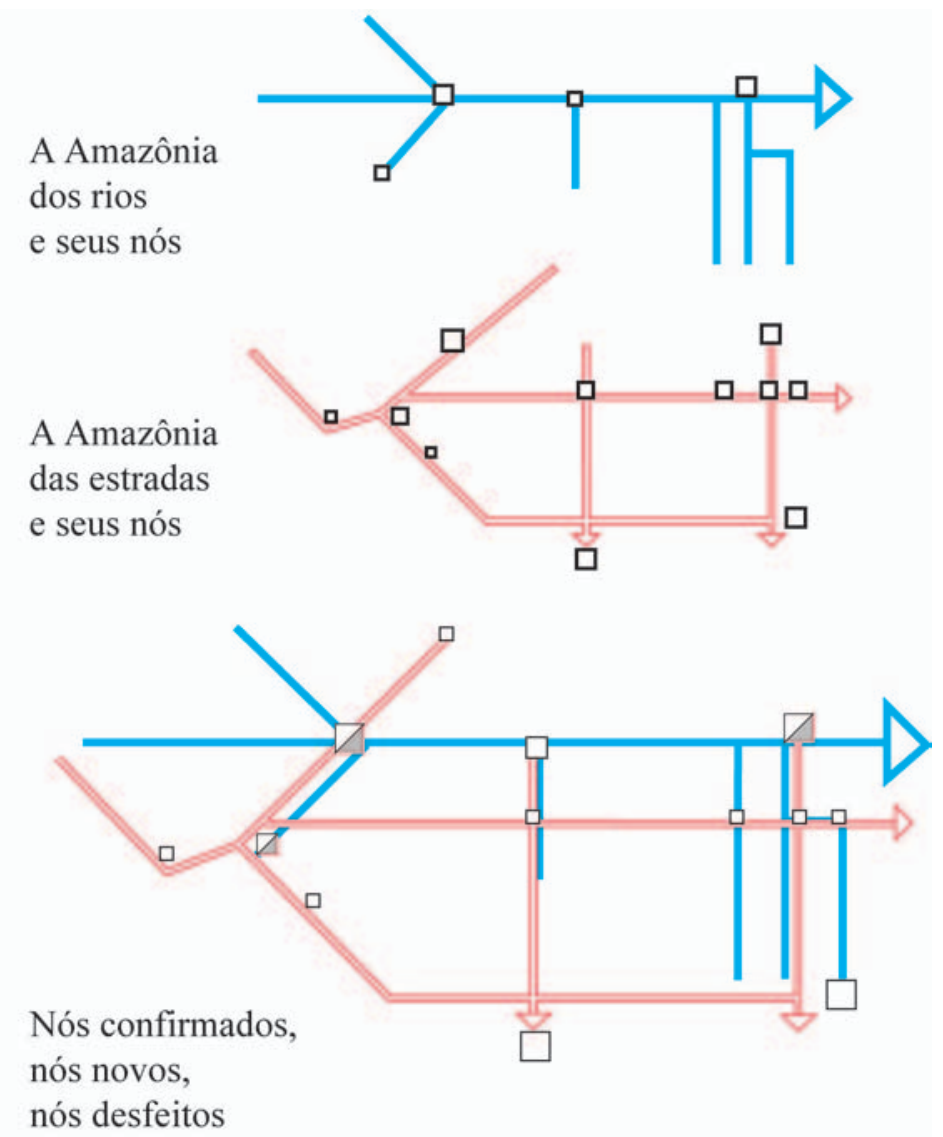

Figura 2 - Rios e rodovias

Cabe aqui uma ressalva: a natureza reticular da organização territorial da Amazônia, acoplada às baixas densidades de ocupação humana, faz com que imensos espaços permaneçam vazios ou quase vazios. Fixando, em uma única imagem (Figura 3), a localização precisa de todos os episódios da história econômica da Amazônia até hoje, Roberto Schmidt de Almeida e Miguel Ângelo Campos Ribeiro revelaram que o espaço realmente aproveitado se resume a corredores que acompanham a rede hidroviária e, secundariamente, a rede rodoviária. Esse fato deve ser levado em consideração quando se trata a Amazônia como uma região de planejamento "normal", onde as unidades territoriais são polígonos 
justapostos, delimitados por fronteiras claras, sem vazios nem superposições. $\mathrm{Na}$ realidade, a maior parte do território da Amazônia ainda permanece intacto, especialmente ao norte da calha do Amazonas, enquanto as franjas meridionais são progressivamente incorporadas ao espaço nacional, acompanhando as diferentes etapas do avanço da fronteira agrícola capitalizada, com caracteres bem distintos.

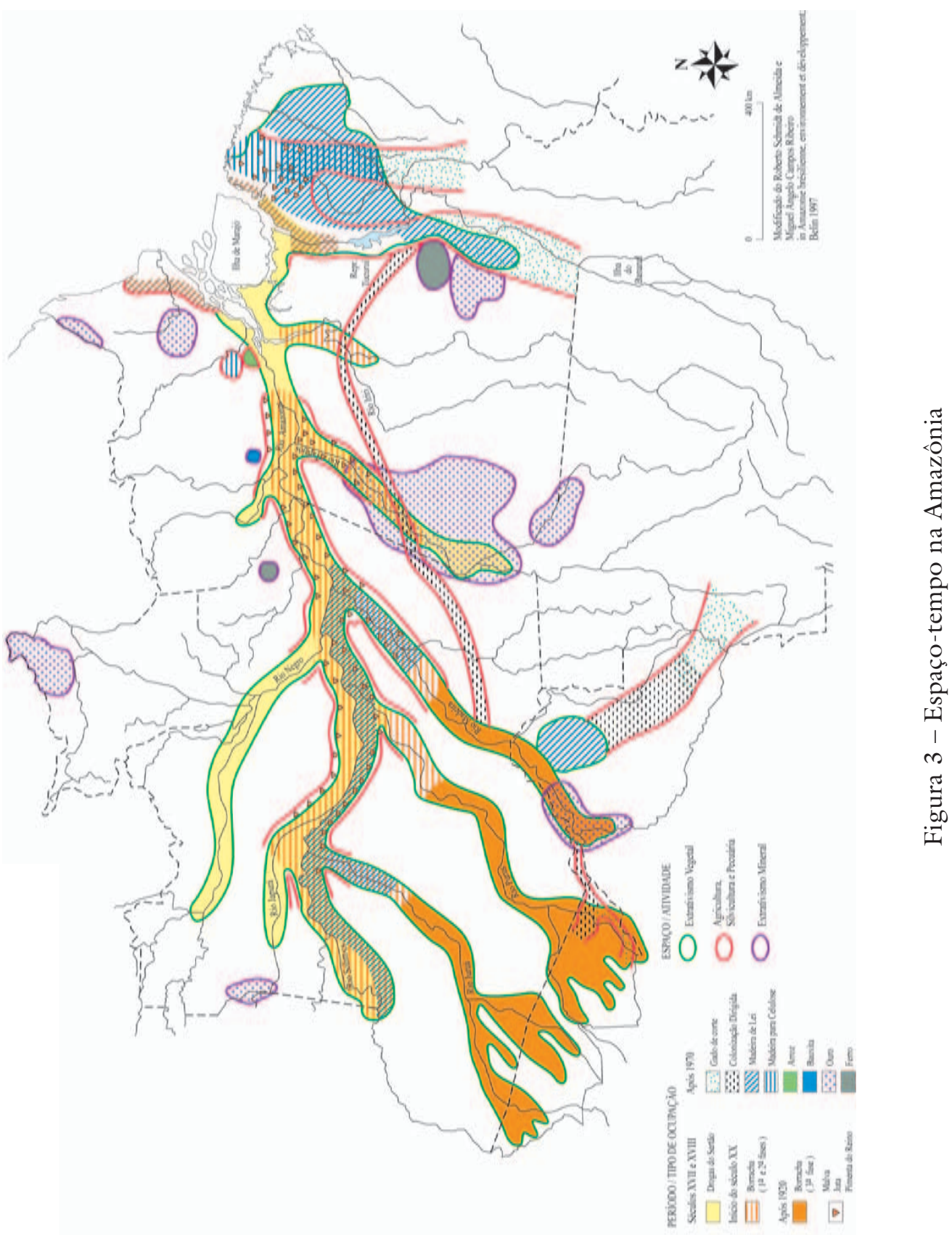

Nesse contexto histórico, como se situam as políticas públicas praticadas nas últimas décadas? 


\section{A Amazônia, fronteira de expansão do Brasil?}

Os programas Brasil em Ação (PPA 1996-1999) e Avança Brasil (PPA 20002003), realizados respectivamente durante o primeiro e o segundo mandato de Fernando Henrique Cardoso, faziam parte de uma estratégia de integração da Amazônia ao espaço produtivo brasileiro e de consolidação da política de integração regional da América do Sul. Para reduzir os gargalos detectados, recursos consideráveis foram aplicados.

Os principais projetos do programa Brasil em Ação visavam à recuperação das estradas BR 364 (Brasília-Acre) e BR 163 (Cuiabá-Santarém); o asfaltamento da BR 174 (Manaus - Boa Vista); a implementação das hidrovias do AraguaiaTocantins e do Madeira; o gasoduto de Urucu e a linha de alta tensão conectando Tucuruí a Altamira e Itaituba.

O programa Avança Brasil, já no segundo mandato, concentrava os investimentos previstos para a Amazônia legal em quatro corredores multimodais de transportes, totalizando 3,5 bilhões de dólares. Mais de $50 \%$ eram destinados ao corredor Araguaia-Tocantins, cerca de 30\% para o corredor Sudoeste, 15\% para o corredor Oeste-Norte e 5\% para o corredor Arco Norte. A estratégia territorial global para a implantação destas ações visava à incorporação efetiva dos territórios de sua parte mais ocidental ao Sul-Sudeste do país, tomando como eixos principais as hidrovias e duas rodovias norte-sul, Cuiabá-Santarém e Porto Velho Manaus - Boa Vista - Venezuela.

Frente a esses grandes projetos, a reação tinha sido fortíssima, porque esses eixos novos deviam atravessar regiões até então intactas e, para algumas, afetadas por uma estação seca bastante longa, os riscos de fogo eram muito sérios. De acordo com Nepstad et al. (2000), as obras de infra-estrutura de transportes, previstos no plano Avança Brasil, deviam provocar impactos graves em quase $187.500 \mathrm{~km}^{2}$, caso se adotasse como limite do seu efeito provável em $50 \mathrm{~km}$ de cada lado das estradas previstas.

O setor ambiental do governo encontrou-se então no meio de uma tempestade, recebendo de um lado apoios, dentro e fora do país, e, de outro, fortes críticas. Circulavam nas redes mundiais informações sobre os progressos e retrocessos dessa política, e pressões permanentes eram exercidas sobre as ações governamentais. Esperando que aparecessem elementos mais sólidos aos serviços das políticas de conservação, essas pressões serviam para travar a implantação das infra-estruturas e para reduzir os impactos. Contribuíam a este fim as ações do Ministério Público federal ou dos estados, baseadas em leis que permitiam respaldar a ação popular, e algumas obras de grande porte, como a hidrovia AraguaiaTocantins, foram embargadas.

Esperava-se, portanto, com grande interesse, a publicação dos projetos inscritos no Programa Plurianual (PPA) 2004-2007, que podia alterá-lo sensivelmente. A decepção foi viva: o PPA contém todos os projetos odiados pelos movimentos ambientalistas (Figura 4). A prioridade dada às estradas e aos equipa- 
mentos hidroelétricas é reforçada, o papel das hidrovias e das ferrovias reduzido, e os investimentos previstos para o gasoduto de Urucu, muito baixos. É verdade que as ferrovias são agora privadas e que a Petrobras tem as suas próprias condições de financiamento e de empréstimo, mas pode-se lamentar que à via aquática e ao uso do gás, respectivamente meio de transporte e fonte energética "limpos”, tenham sido preferidas as infra-estruturas de impactos ecológicos mais fortes, as estradas e barragens.

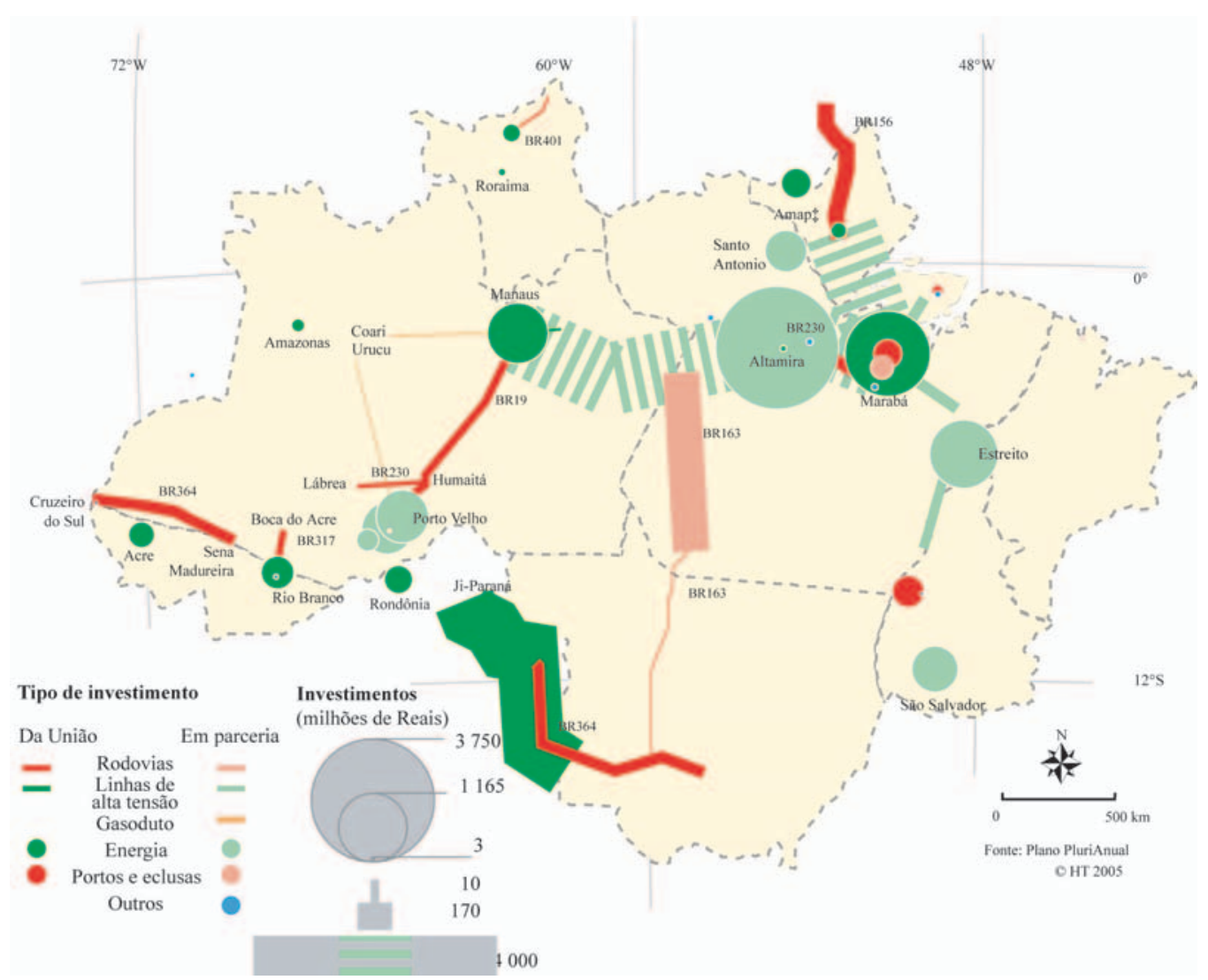

Figura 4 - Investimentos em infra-estruturas no Plano Plurianual 2004-2007

Entre os investimentos diretos do Estado federal, os mais significativos são da área energética, o desenvolvimento da usina de Tucuruí (1,814 milhões de reais), a extensão da rede interconectada do Mato Grosso a Rondônia e ao Acre (1,056 milhões de reais), o equipamento para Manaus (915 milhões de reais) e de diversos equipamentos de menor porte nas cidades e as povoações de cada estado. As estradas vêm logo atrás, a BR 156 (ligando Brasil à Guiana), a BR 230 (Transamazônica), a BR 364 e a BR 319 ligando respectivamente ao Acre e a Manaus, prolongando e facilitando a penetração para o noroeste.

A construção da barragem de Belo Monte (cuja potência instalada prevista é quase igual à de Itaipu), várias vezes adiada devido à oposição dos movimentos 
ecologistas, é dotada apenas de dez milhões de reais, mas 3,750 milhões de reais são inscritos no título dos investimentos em parceria. O mesmo ocorre para as barragens do Madeira e do Tocantins, cujos custos seriam compartilhados com as empresas concessionárias, e o asfaltamento da estrada BR 163, Cuiabá-Santarém, detestada pelos "verdes" mas ardentemente desejada pelos produtores de soja, que vêem nela o meio de escoar a sua produção para o norte, em vez fazer um longo desvio, via os portos do Sul.

Se as somas previstas para esses projetos são impressionantes, outro programa as faz parecerem pequenas (a tal ponto de não poder ser desenhado na escala real no mapa), os 4,2 bilhões de reais previstos para expandir as linhas de alta tensão da usina de Tucuruí até Macapá e Manaus. As dificuldades da obra são tamanhas, haja vista a localização de ambas as cidades, na outra margem do Amazonas (que deverá, portanto, ser cruzado) e as somas em jogo tão grandes que se pode duvidar da concretização deste projeto (que nunca tinha sido mencionado antes) nos quatro anos do Plano.

Trata-se, por conseguinte, de um conjunto de projetos de cunho claramente "desenvolvimentista", não muito conformes aos princípios anunciados durante a campanha presidencial que prolongam, sem ambigüidade, os esforços do governo anterior e não levam muito em conta as suscetibilidades dos movimentos ambientalistas.

Tentando sintetizar os efeitos espaciais das políticas públicas, o mapa (Figura 5) distingue situações diversas. Dentro de estruturas definidas principalmente pelo quadro físico e pela repartição atual duma população ainda em fase de conquista pioneira, as políticas públicas na Amazônia tomam três formas principais: política de conservação e política social na calha dos rios e na Amazônia ocidental, política de produção nas periferias sul e leste, política e penetração ao longo de certas hidrovias e rodovias. A resultante territorial das interações entre um quadro ainda maleável e essas políticas seria o seguinte:

A velha Amazônia dos rios, no centro da bacia, continua ignorada pelas políticas públicas, em sua maior parte, com a exceção notável das cidades (onde, é preciso lembrar, vivem mais de $60 \%$ da população regional).

O arco externo da Amazônia legal já está incorporado ao espaço nacional, os planaltos que eram cobertos pelos cerrados e pela floresta decídua foram transformados por uma potente economia agropecuária em zona de produção e de escoamento de grãos.

Uma franja intermediária, na parte dianteira da frente de expansão, encontra-se em uma situação mais indecisa, diversos cenários podem ser imaginados, dependendo do rumo que se quer dar às políticas públicas para a Amazônia.

O norte e o oeste da região ainda formam um espaço de reserva, no momento quase que unicamente afetado por políticas de conservação. Será o seu destino de continuar nesse papel? 


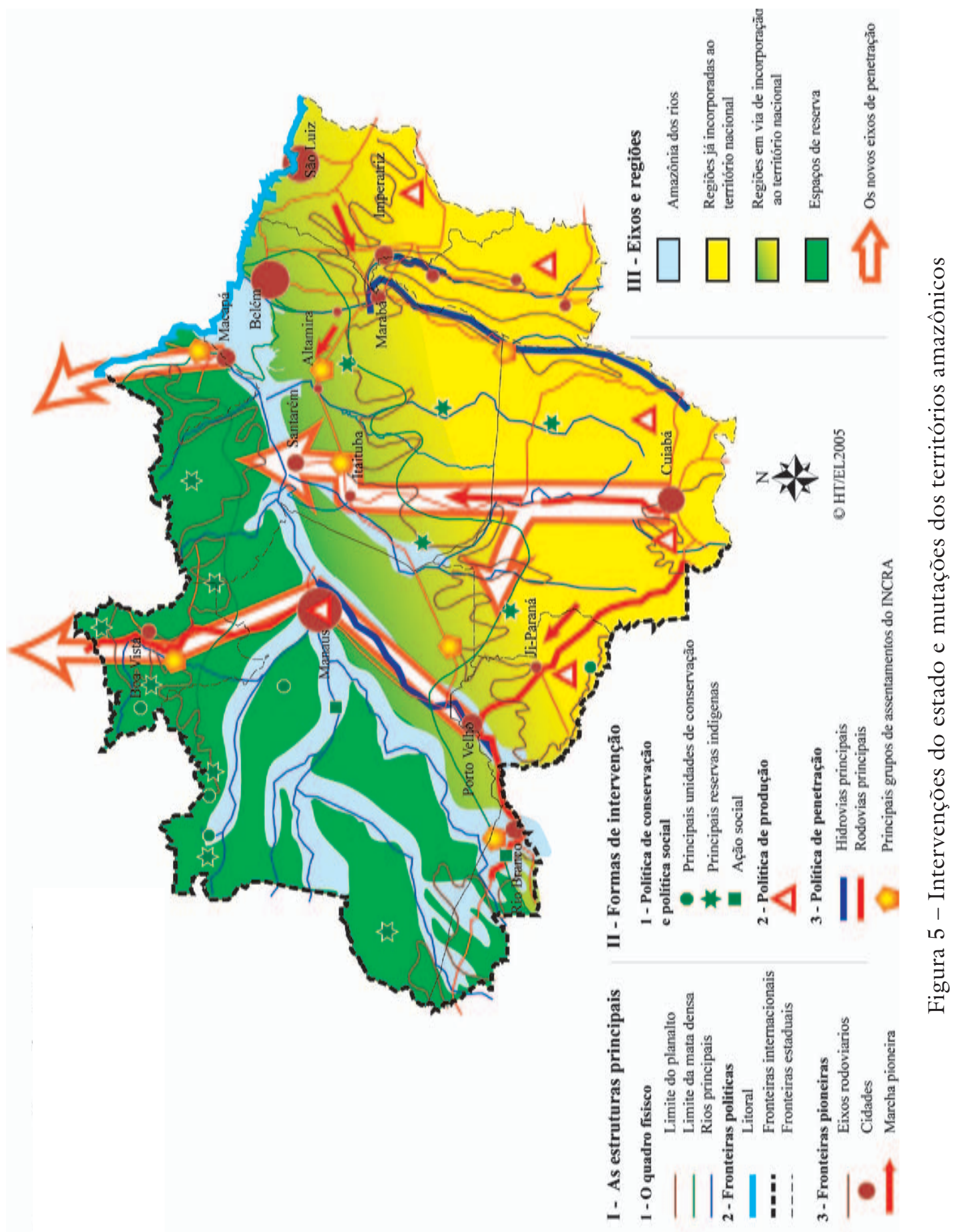


Finalmente, o fato novo é a criação de três novos eixos de penetração rumo ao norte, um principal ao longo da BR 163, dois outros menores de Manaus até a fronteira da Venezuela e do Amapá à Guiana francesa, ambos podendo convergir para fechar um futuro "arco norte", abarcando as Guianas. Qualquer política para a Amazônia, seja ela de conservação ou de desenvolvimento sustentável integrado, deverá levar em conta essa tendência.

\section{A Amazônia, de periferia do Brasil a centro do continente}

Convém aqui lembrar que a Amazônia brasileira, mesmo sendo tão extensa, não é toda a bacia Amazônica (Figura 6): se ela de fato representa 62\% do total, os $38 \%$ restantes pertencem a oito países vizinhos, hoje seus parceiros na OTCA (Organização do Tratado de Cooperação Amazônica).

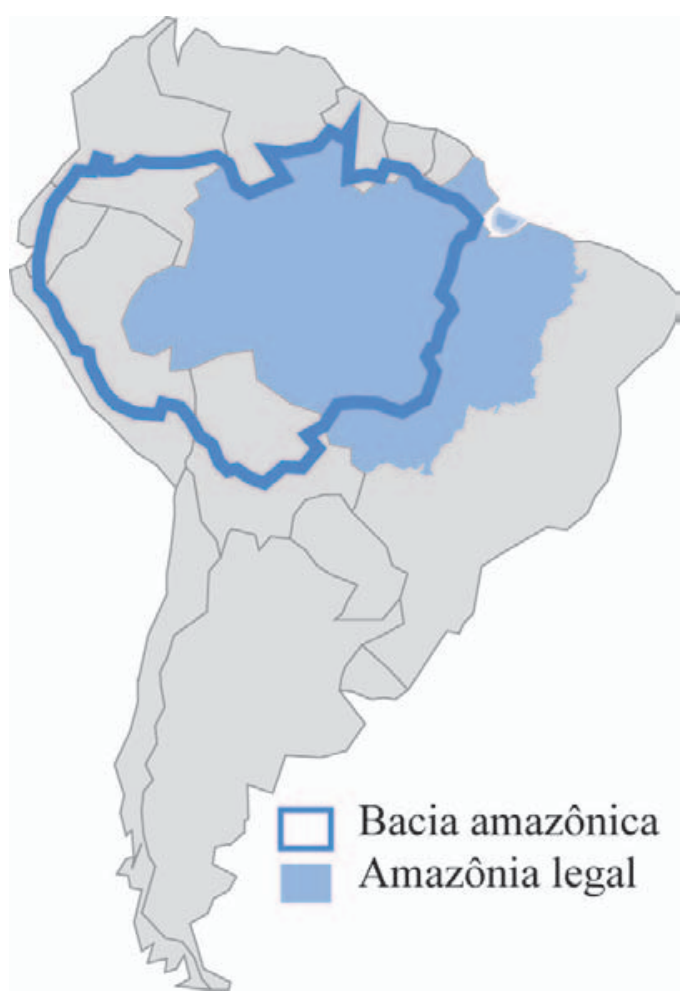

Figura 6 - Amazônia brasileira

E, de fato, entre os fatores mais susceptíveis de produzir efeitos profundos na região, a abertura de ligações com os países vizinhos, até então praticamente impossíveis, é um dos mais potentes. Dos vizinhos amazônicos do Brasil, só a Colômbia não é hoje acessível por um eixo rodoviário (e não o será tão cedo, se a atual situação político-militar se prolongar). Vale notar que os eixos imaginados há pouco mais de vinte anos pelos teóricos da geopolítica militar (notadamente o general Meira Mattos, 1980), foram quase todos realizados, mesmo considerando-se que o contexto mudou radicalmente, já não se trata mais de conquista e de satelitização, mas de cooperação transfronteiriça e de integração continental. 
Obviamente, essa transformação não converterá inteiramente a região, mas ela tem efeitos discriminantes: alguns eixos foram privilegiados, outros deixados de lado. As infra-estruturas planejadas e financiadas pelo Programa Brasil em $A c ̧ \tilde{a} o$ concentraram-se em boa parte ao longo de dois eixos, um deles norte-sul, o Araguaia-Tocantins e o outro, aquele que liga São Paulo (e, portanto, o Mercosul) ao Caribe, via Cuiabá, Manaus e Boa Vista. Os investimentos alocados estão configurando um novo eixo continental que oferece uma alternativa - passando pelo território brasileiro - ao principal eixo Norte-Sul atual, a Carretera Panamericana que conecta a Patagônia ao Panamá.

No estudo dos eixos de integração na América do Sul realizado pelo IIRSA (Figura 7) para selecionar os que mereceriam maior atenção e investimentos, nota-se que a Amazônia é cruzada por vários eixos, seja na direção leste-oeste (associando a rede fluvial amazônica a rodovias para atingir o Pacífico), seja de norte a sul, graças à mesma rede $\mathrm{e}$ às rodovias ligando o Brasil às Guianas. $\mathrm{A}$ Amazônia torna-se o centro do continente, em vez de ser a periferia dos países que a compõem, mesmo não sendo a parte do continente onde passam os fluxos mais densos, os quais passam mais ao sul.

Finalmente, mesmo com a temeridade de tentar resumir cinco séculos de história em uma imagem sintética (Figura 8), pode-se mostrar os deslocamentos do principal eixo de propagação e de inovação na região, os que foram e o que serão provavelmente os futuros "pontos quentes" da região.

Da chegada dos primeiros colonos europeus até os anos de 1960 - o período mais longo na história plurissecular da Amazônia - o eixo principal de penetração foi o rio Amazonas e seus afluentes, sempre percorridos da foz para montante.

Nos anos de 1960, o eixo principal passou a ser uma direção sul- norte, ao longo da rodovia Brasília-Belém.

Nos anos de 1970, o fluxo principal ia do leste para o oeste, ou do sudeste para o noroeste, ao longo das novas rodovias, BR 364 e Transamazônica.

Nos anos de 1980 e no início dos anos de 1990, por falta de uma política amazônica bem definida, diversas direções de propagação se misturavam (sulnorte, oeste- leste, leste-oeste), uma indecisão que reflete bem as incertezas dessa "década perdida".

Finalmente, retoma-se hoje uma tendência a um movimento sul- norte, ao longo do eixo Araguaia-Tocantins, da BR 163 e dos eixos Manaus-Venezuela e Amapá-Guiana Francesa.

A Amazônia está, portanto, vivendo um momento de mutações, o qual transforma até as suas dimensões. Não no sistema métrico, onde ela mantém os milhões de metros cúbicos de água, de quilômetros quadrados de florestas e de milhões de espécies ainda desconhecidas, que fazem dela uma das principais zonas de biodiversidade do planeta. Mas na métrica mais sutil do peso demográfico, econômico e social, na topologia dos transportes, onde o tempo de percurso conta mais do que o espaço bruto, e as ligações efetivas mais do que as proximidades. 


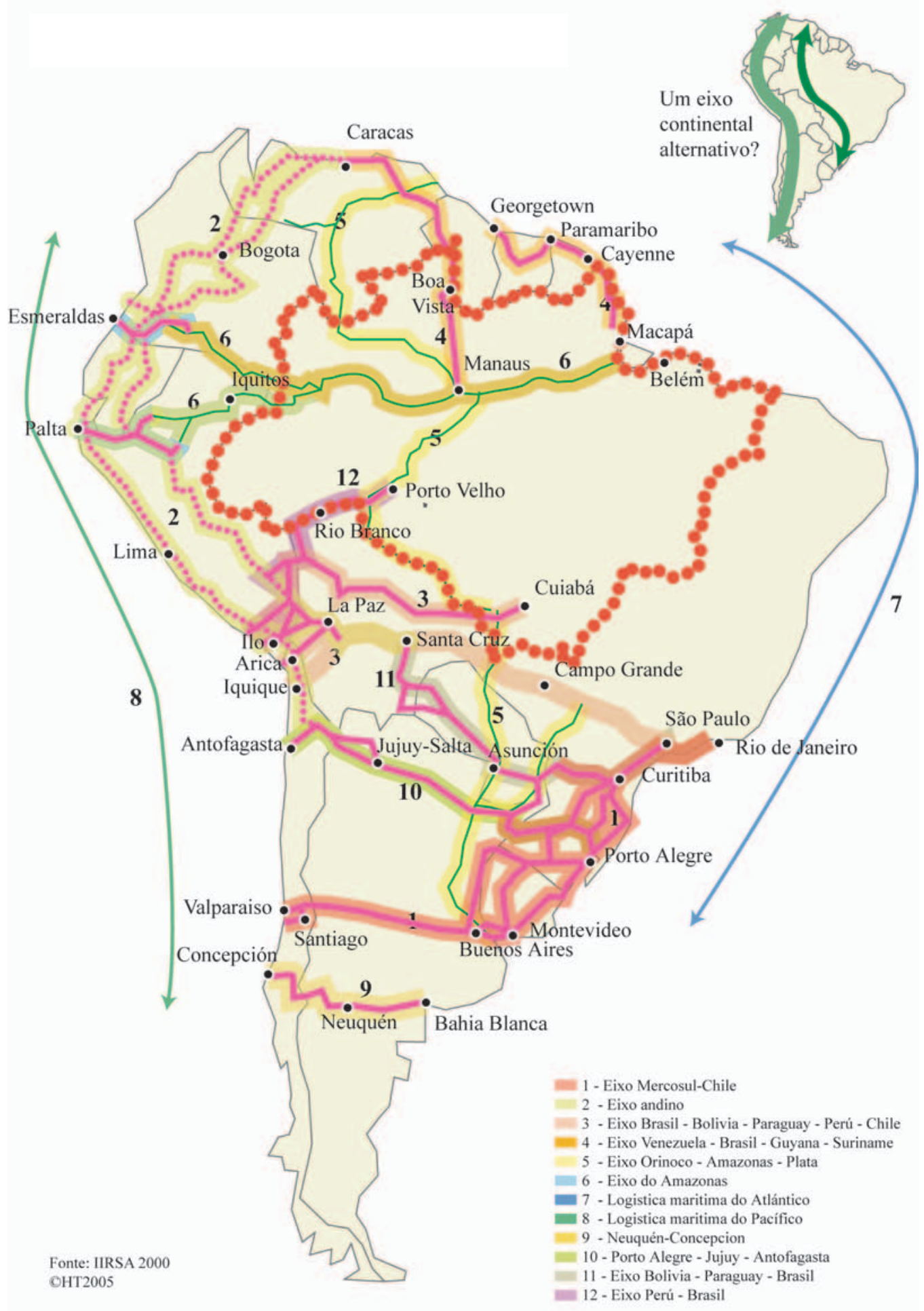

Figura 7 - Eixos de integração na América Latina 


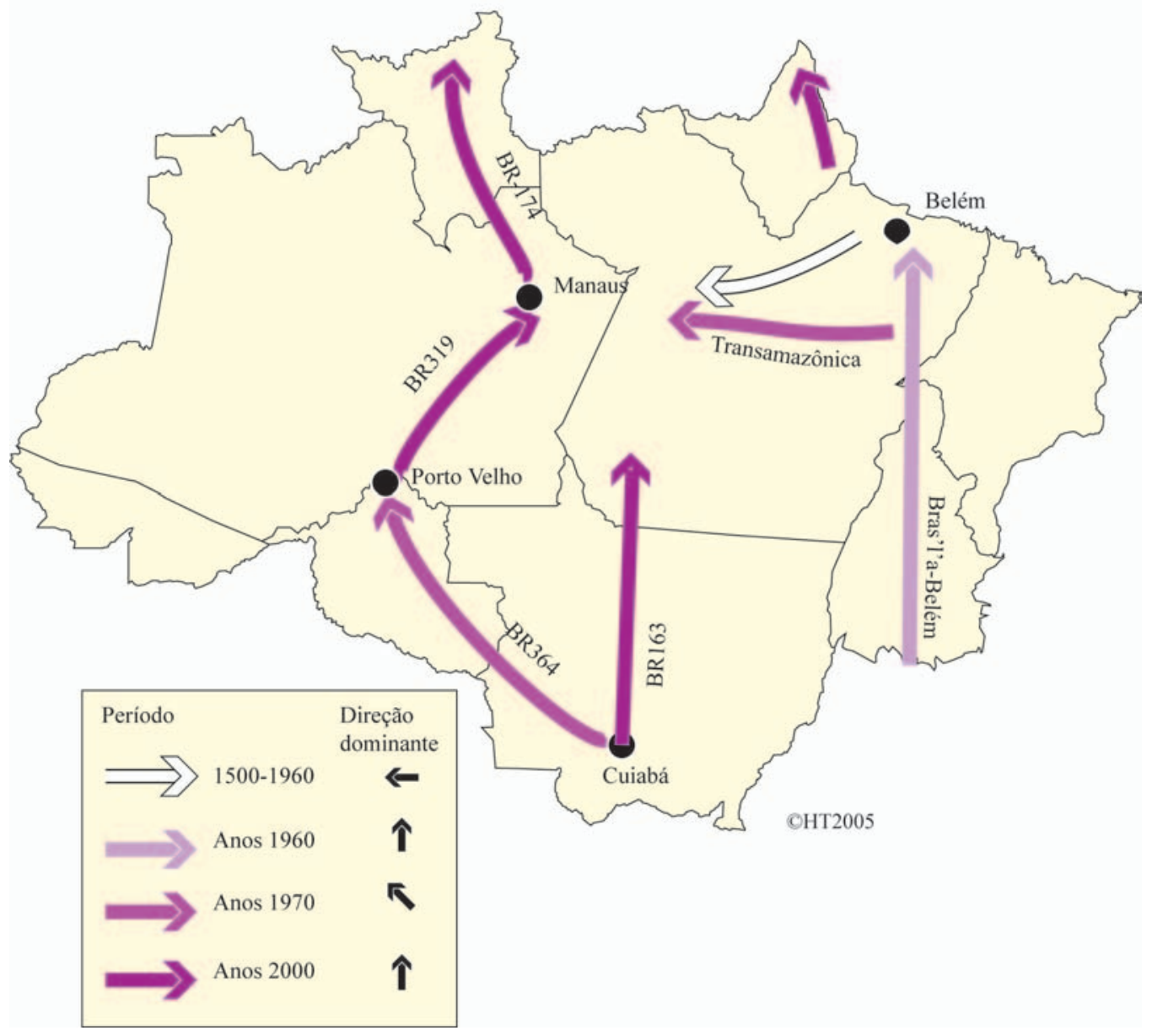

Figura 8 - Eixos de ontem, de hoje e de amanhã

Bibliografia

AMIGOS DA TERRA. A Amazônia e o novo PPA: como aprender com as lições do Avança Brasil. São Paulo, multigr., fev. 2003, 12 p.

Coligação Lula Presidente. O lugar da Amazônia no desenvolvimento do Brasil. Programa de governo 2002, coligação Lula Presidente, Belém, multigr., set. 2002, 34 pp.

MEIRA MATTOS, General. Uma geopolitica pan-amazônica. Rio de Janeiro, José Olympio, 1980.

MELlO, Neli de. Políticas públicas territoriais na Amazônia Brasileira: conflitos entre conservação ambiental e desenvolvimento, 1970 a 2000. São Paulo/ Nanterre, Departamento de Geografia, FFLCH-USP/Université de Paris X, 2002. 
MELLO, Neli de, PASQUIS, R. e THÉRY, H. “L'Amazonie 'durable' de Marina Silva”. Em ROLLAND, Denis e CHASSIN, Joëlle (eds.). Pour comprendre le Brésil de Lula. Paris, L'Harmattan, 2004, pp. 169-185.

MELLO, Neli de e THÉRY, H. “L'État brésilien et l'environnement en Amazonie: évolutions, contradictions et conflits”. L’Espace Géographique, vol. 1, t. 32, 2003, pp. $3-20$.

THÉRY, H. “Pesos e medidas da Amazônia”. Em SAYAGO, Doris; TOURRAN, JeanFrançois e BURSZTYN, Marcel (orgs.). Amazônia, cenas aos cenários. Brasília, Editora da Universidade de Brasília, 2003, pp. 9-15.

Ministério da Integração Nacional, Ministério do Meio Ambiente. Plano Amazônia Sustentável-PAS, vol. 1, diagnóstico e estratégia. Brasília, multigr., out. 2003, 75 p.

Ministério do Meio Ambiente. Amazônia sustentável: contribuição para a elaboração de um programa de Desenvolvimento Sustentável para a Amazônia e subsídios para o Plano Plurianual. MM, Brasília, multigr., maio 2003, 10 pp.

NEPSTAD, D. et al. Avança Brasil: os custos ambientais para a Amazônia. Belém, Gráfica e Editora Alves, 2000.

PASQUIS R. (coord.); NUNES, B.; LE TOURNEAU, F. M.; MACHADO, L. e MELLO, N. A. de. As Amazônias, um mosaico de visões sobre a região. Banco Mundial, CDS UnB, Brasília, 44p. + anexos, 2003, 45 pp.

RESUMO - ESTE ARTigo analisa inicialmente o peso real da Amazônia no Brasil, em termos econômicos e humanos. Em seguida, avalia as políticas públicas na Amazônia, cuja linha diretriz parece ser de mantê-la em um papel de fronteira de expansão. Finalmente, re-situa a região na América do Sul, que passa subitamente de periferia a centro do continente.

ABSTRACT - THE ARTICLE analyzes first the actual weight of Amazonia in Brazil, in economic and human terms. Then, it evaluates the public policies in Amazonia, whose main line seems to be to maintain it as an expansion frontier. Finally it puts in perspective the region inside South America, where it passes suddenly from periphery to center of the continent.

Palavras-chave: Amazônia, Geopolítica, Políticas Públicas, Estratégias.

Keywords: Amazon, Geopolitics, Public Policies, Strategies.

Hervé Théry é diretor de pesquisa no CNRS-Credal e diretor da Unidade Mista de Pesquisa ENS/IRD Temps (Território e Globalização nos Países do Sul). Entre diversas funções exercidas, foi diretor do GIP Reclus, professor na École Normale Supérieure de Paris e diretor de sua seção de geografia. Atualmente, é pesquisador convidado no Centro de Desenvolvimento Sustentável da Universidade de Brasília - CDS. O seu Atlas do Brasil, disparidades e dinâmicas do território brasileiro (em colaboração com Neli Aparecida de Mello) está no prelo na Editora da Universidade de São Paulo (Edusp).

Texto recebido em 10 de janeiro de 2005 e aceito para publicação em 26 de janeiro de 2005 . 